كزينش لاينهاى متحمل به شورى در آفتابكَردان روغنى با استفاده از برخى صفات فيزيولوزيك أنتابكرد

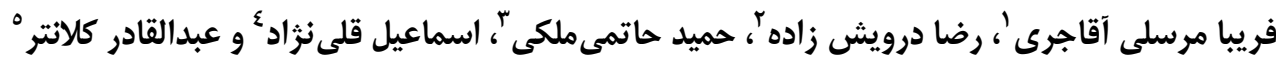

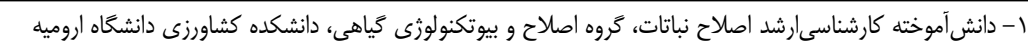

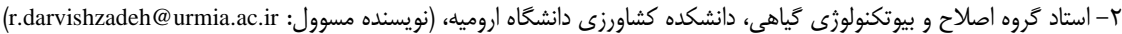

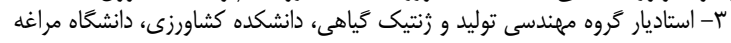

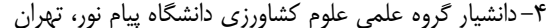

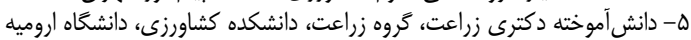

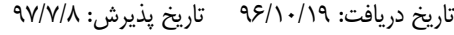

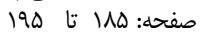

جكيده

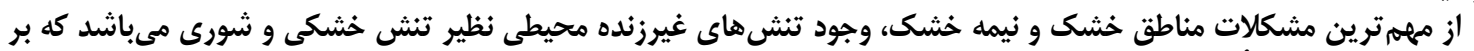

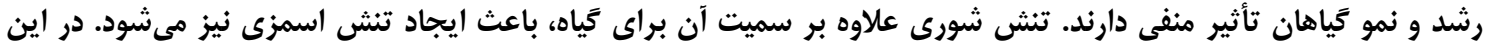

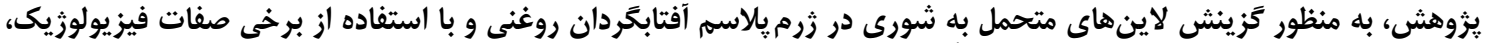

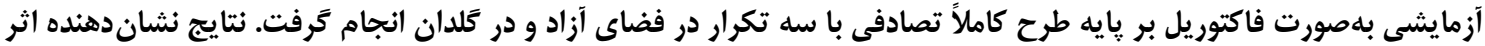

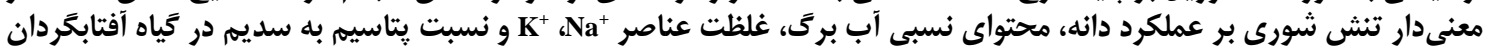

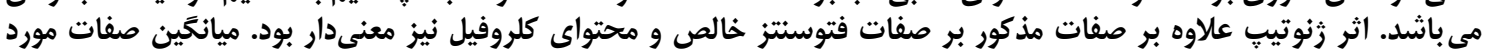

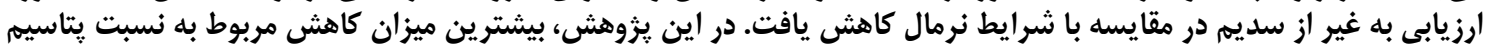

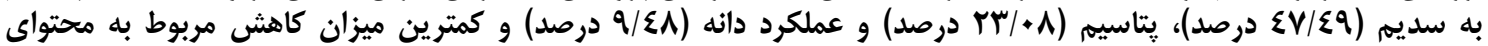

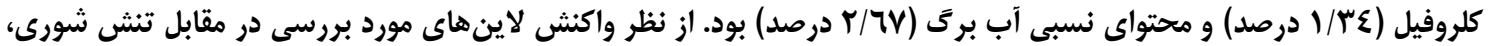

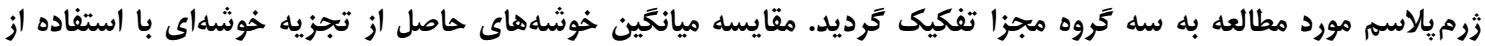

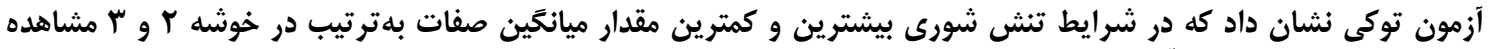

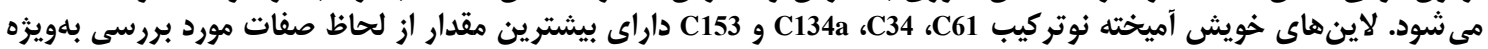

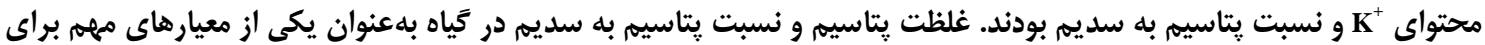

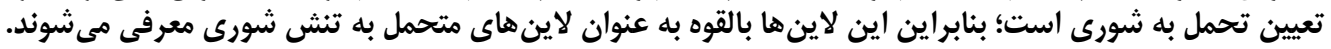

وازههاى كليدى: آفتابكردان روغنى، تنش شورى، فتوسنتز خالص، محتواى نسبى آب برك، نسبت يتاسيم به سديم

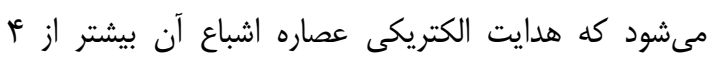

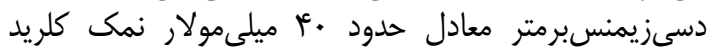

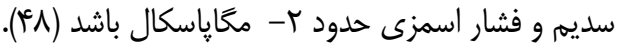

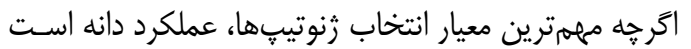

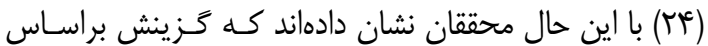

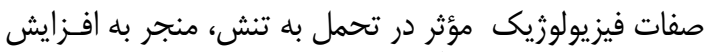

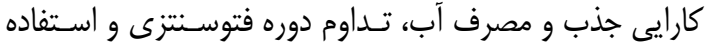

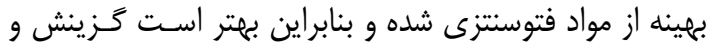

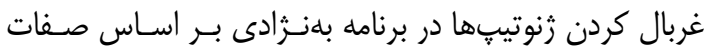

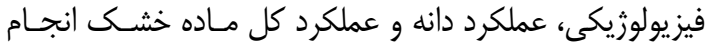

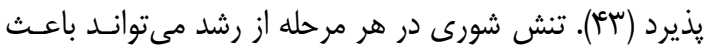

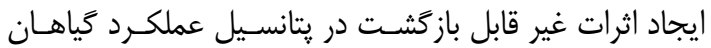

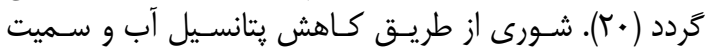

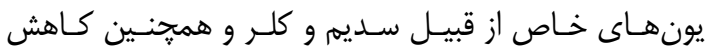

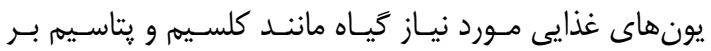

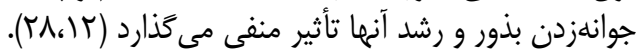

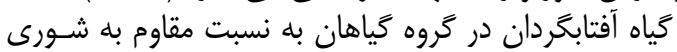

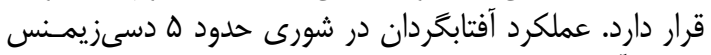

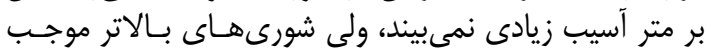

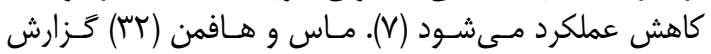

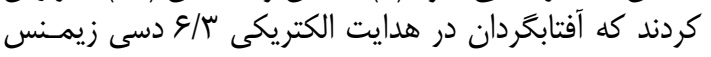

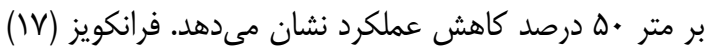

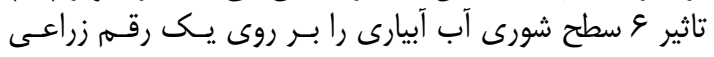

آفتابخر دان با نام علمى .Helianthus annuus L.

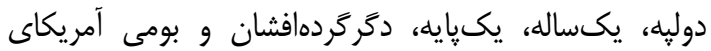

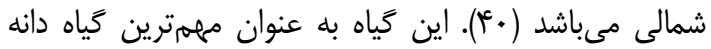

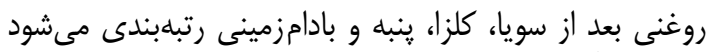

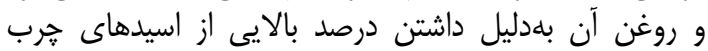
غيراشباع و سطوح يايين كلسترول محبوبيت بيشترى دارد دارد (1).

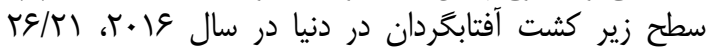

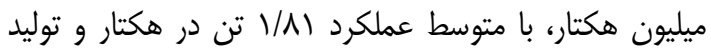

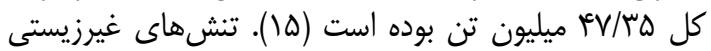

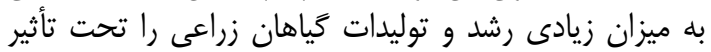

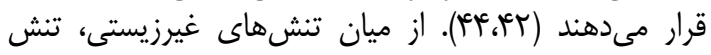

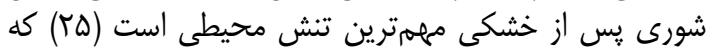

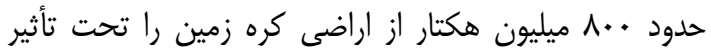

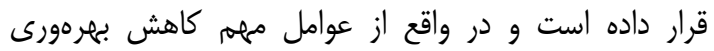

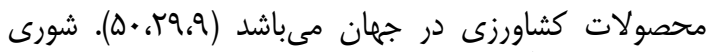

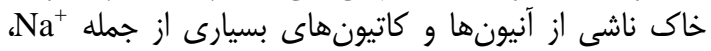

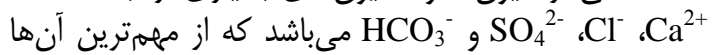

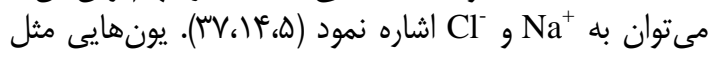

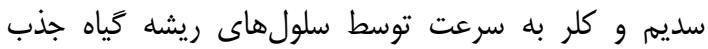

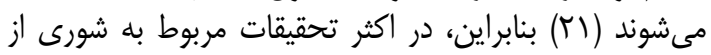

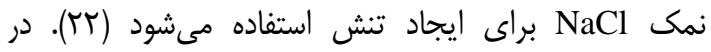

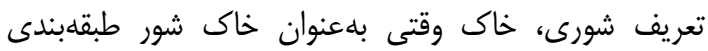


محتواى كلروفيل و نسبت

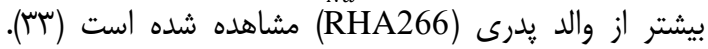

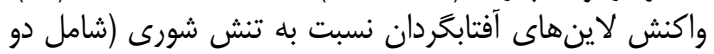

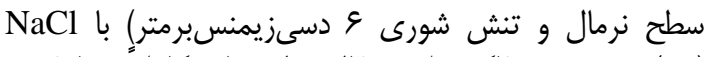

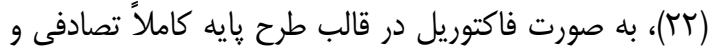

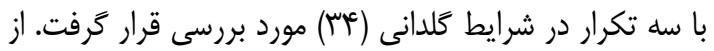

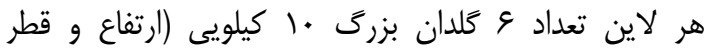

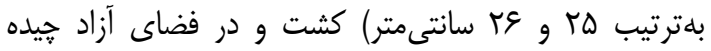

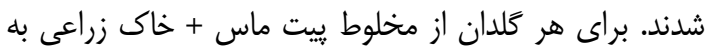

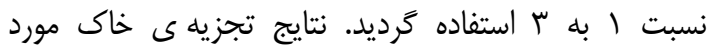

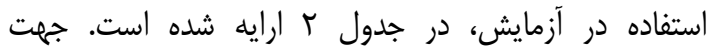

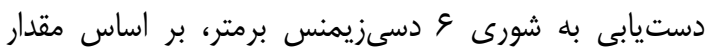

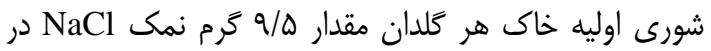
ه ب...

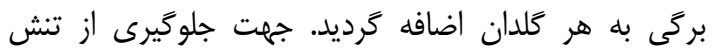

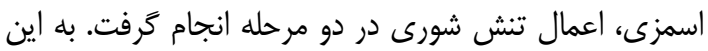

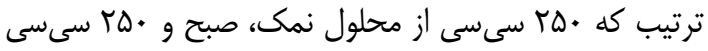

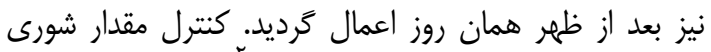

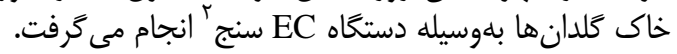

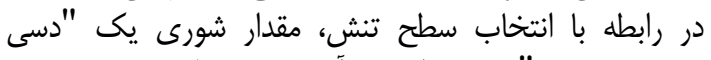

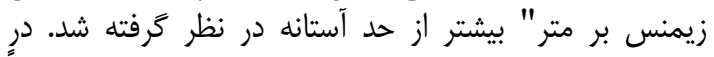

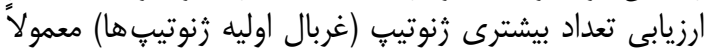

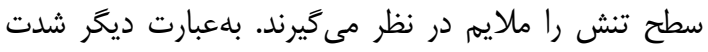

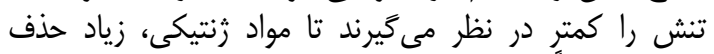

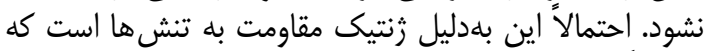

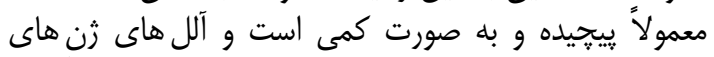

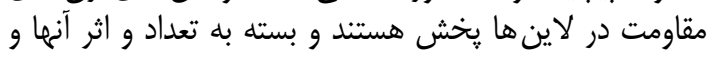

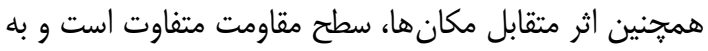

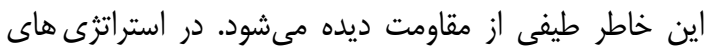

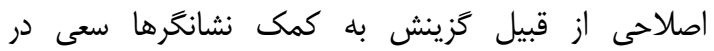

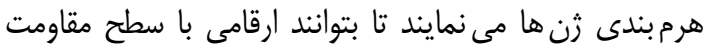

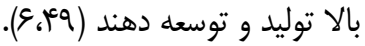

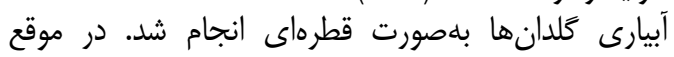

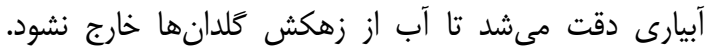

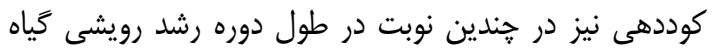

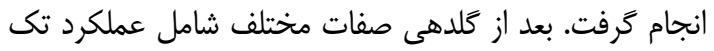

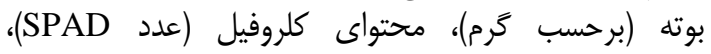
فتوسنتز خالص (بر حسب ميكروم) محتول برول بر مترمربع در ثانيه)،

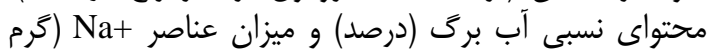

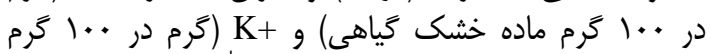

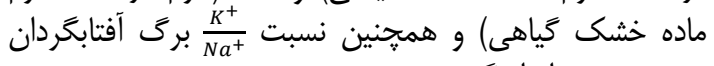

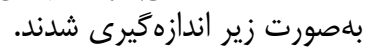

عناصر

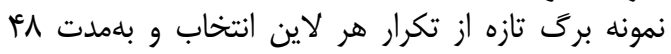

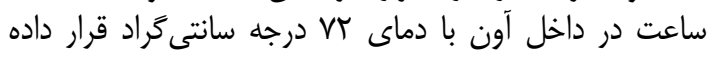

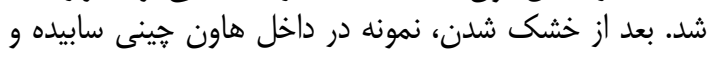

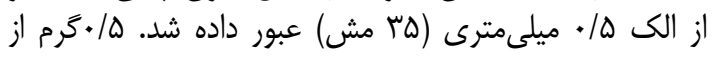

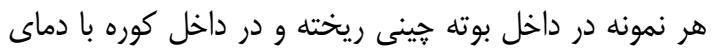

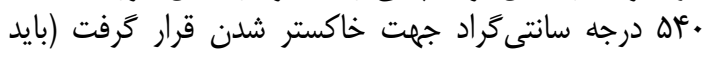

آفتابكردان مطالعه كردند. نتايج تحقيق نشان داد كه عملكـرد

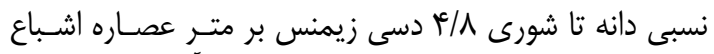

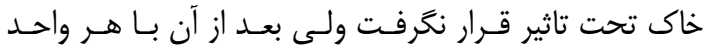

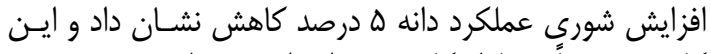

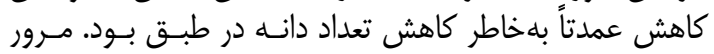

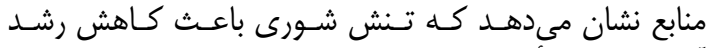

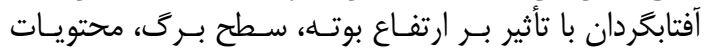

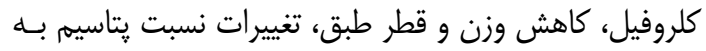

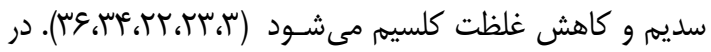

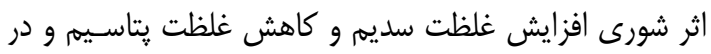

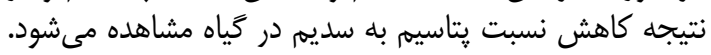

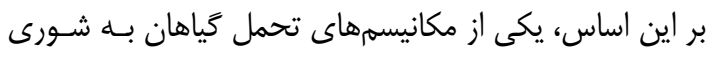

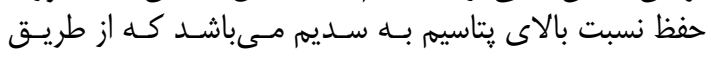

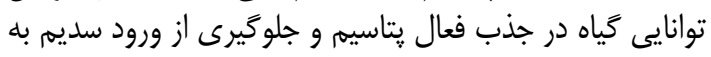

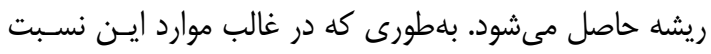

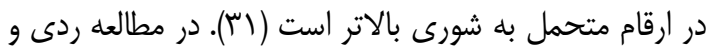

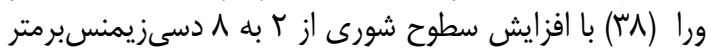

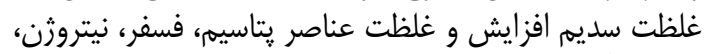

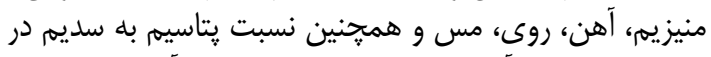

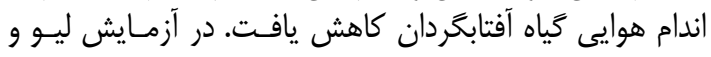

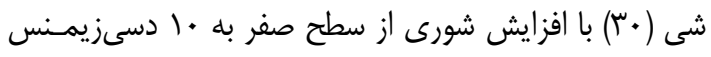

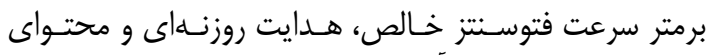

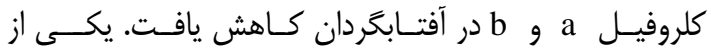

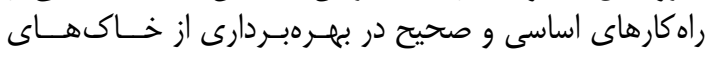

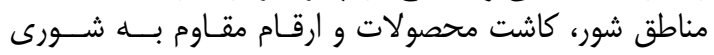

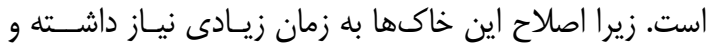

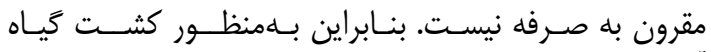

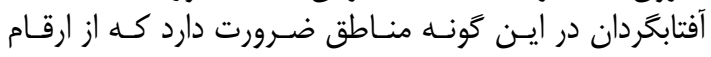

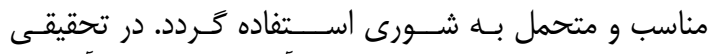

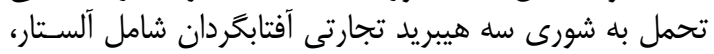

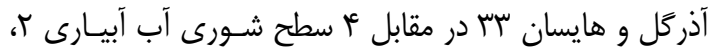

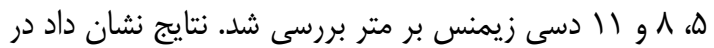

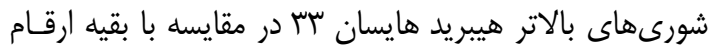

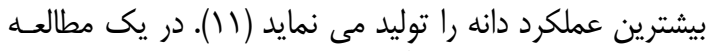

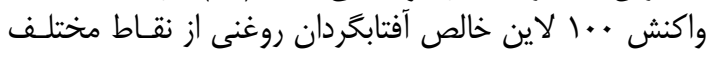

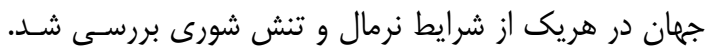

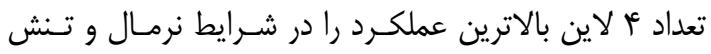

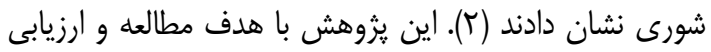

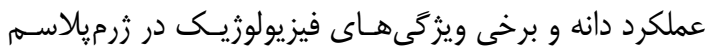

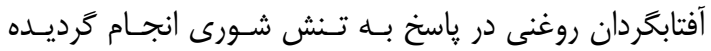

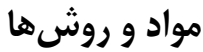

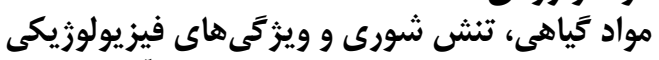

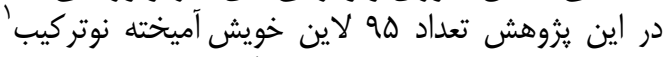

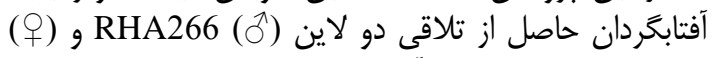

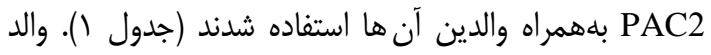

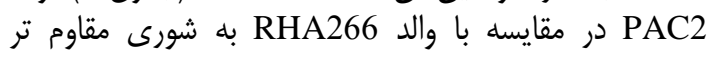
است. در شرايط تنش شورى عملكرد دانه، وزن . ..1 دانه، 


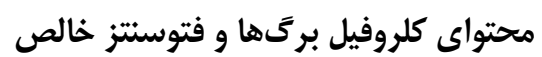

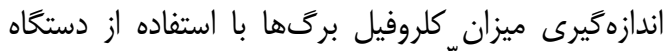

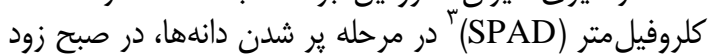

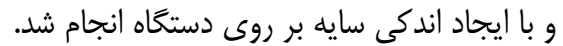

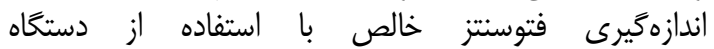

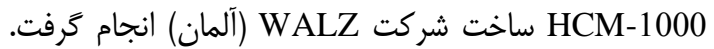

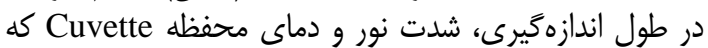

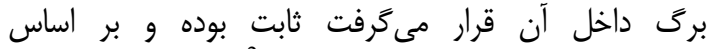

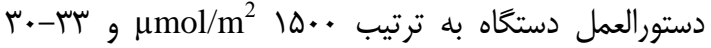

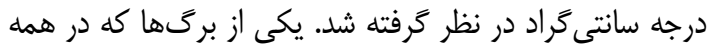

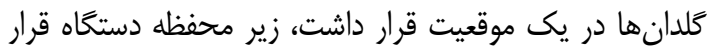

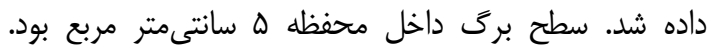

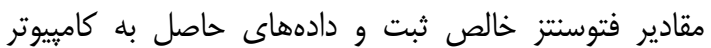

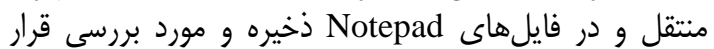

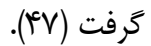

\section{تجزيه و تحليل دادهها}

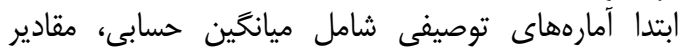

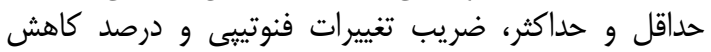
صفت در شرايط تنش شورى شري (ميانكين صفت درئ در شرايط

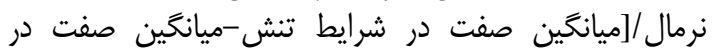

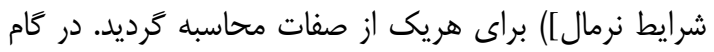

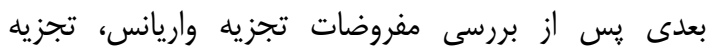

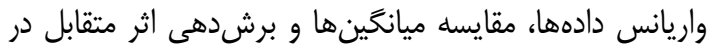

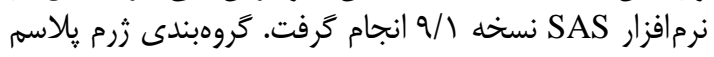

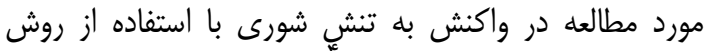

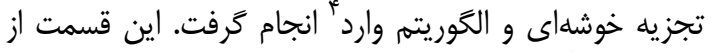
تجزيههاى آمارى با استفاده از نرم افزار انجام شد.
توجه شود كه خاكستر به رنغ سفيد در آمده باشد در غير

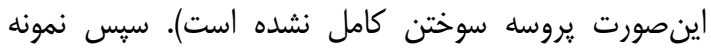

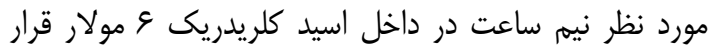

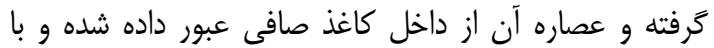

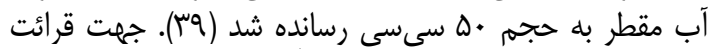

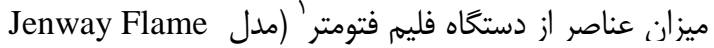
(photometer PFP7

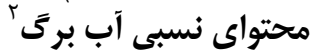

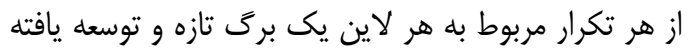

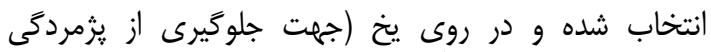

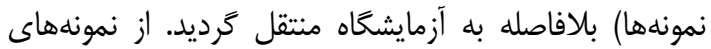

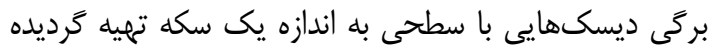

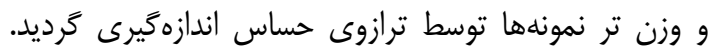

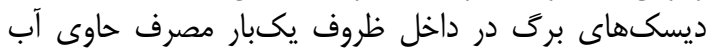

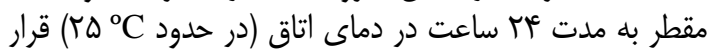
داده شد. بعد از طى زمان مان مذكور ابتدا آب اضافى دافى نمونهانها

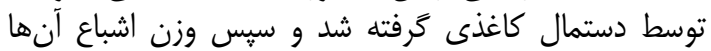

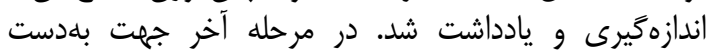

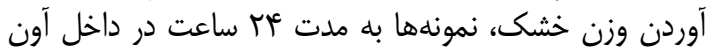

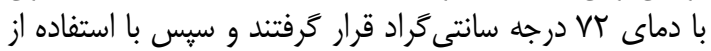

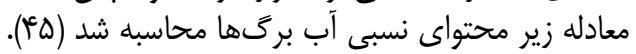

$$
R W C(\%)=\frac{F W-D W}{T W-D W} \times 100
$$

$$
\text { وزر خشك برى وزن تر برى (DW) مى (DW)، وزن اشباع. برى (TW) و }
$$


Table 1. Characteristics of studied oily sunflower genotypes

جدول 1- مشخصات زنوتيڤهاى آفتابخردان روغنى مورد مطالعه

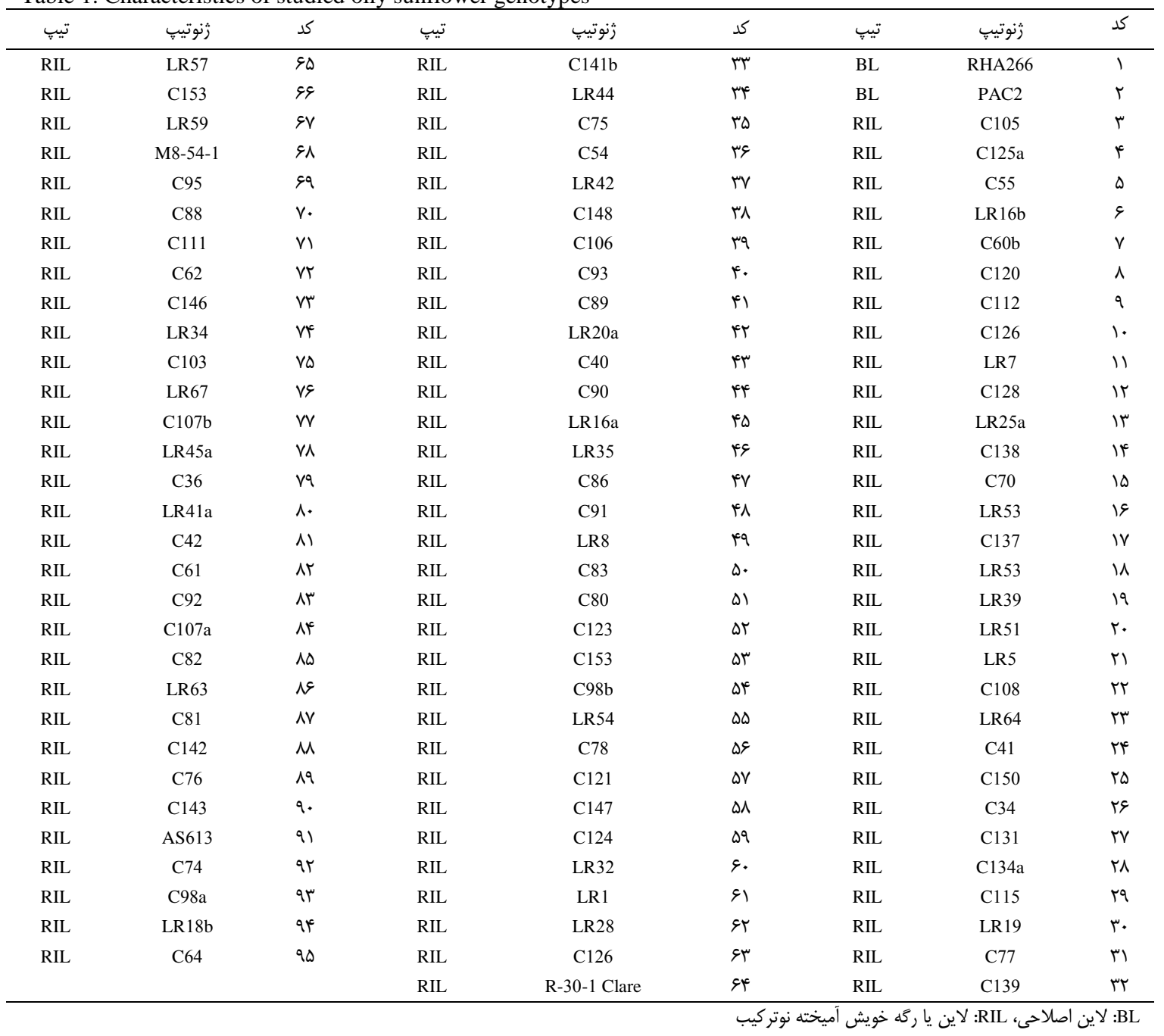

Table 2. Results of soil analysis used in the present experiment

جدول r- نتايج تجزيه خاك مورد استفاده در اين آزمايش

\begin{tabular}{|c|c|c|c|c|c|c|c|c|c|c|}
\hline $\mathrm{pH}$ & $\mathrm{EC}$ & $\mathrm{OC}$ & $\mathrm{OM}$ & $\mathrm{CaCO} 3$ & Clay & Silt & Sand & Texture & $\mathrm{K}$ & $P$ \\
\hline 7.96 & 1.09 & 0.68 & 1.17 & 12.0 & 24 & 40 & 36 & Loam & 218.96 & 16 \\
\hline
\end{tabular}

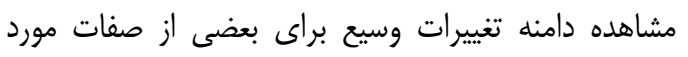

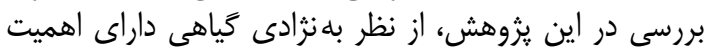

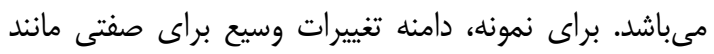

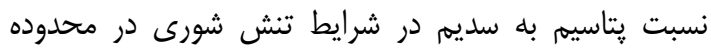

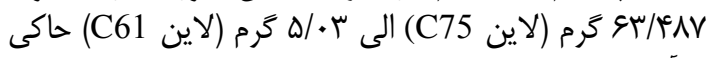

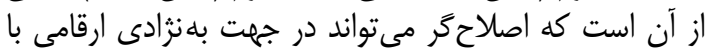

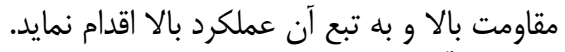

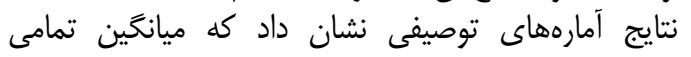

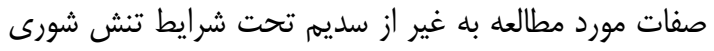

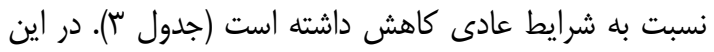

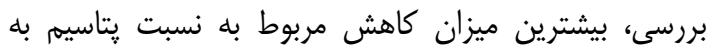

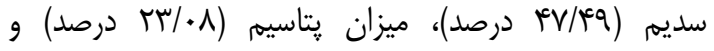

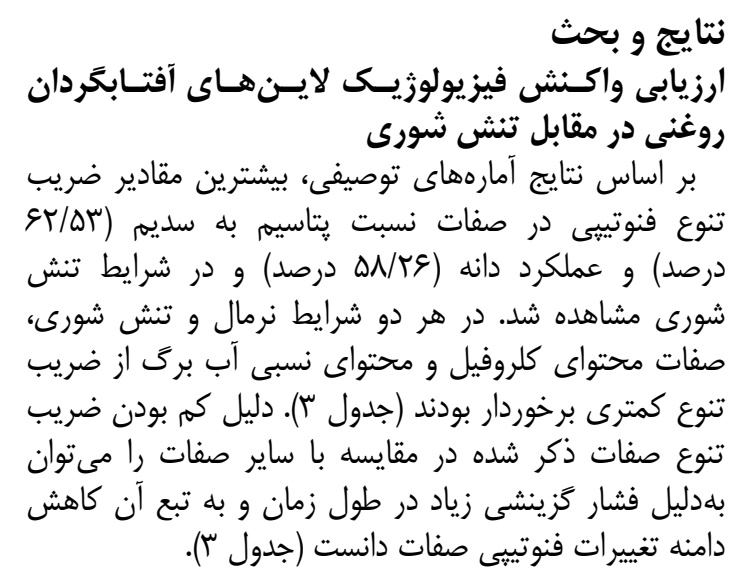


والدين و لاينهاى C82، C78 و C124 داراى ميانخين كمتر

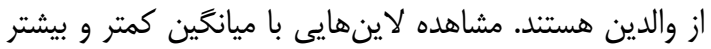

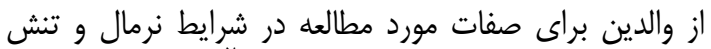

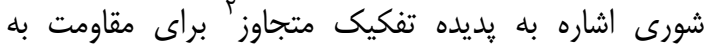

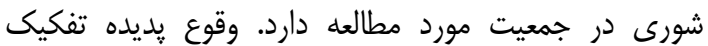

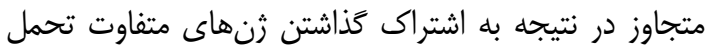

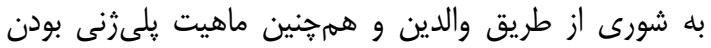

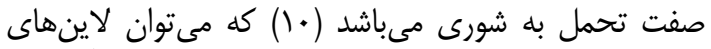

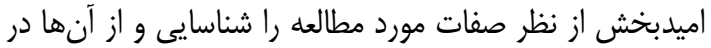

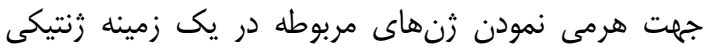

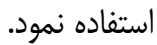

بر اساس نتايج تجزيه واريانس دادهها، بين لاينهاى ماد مورد

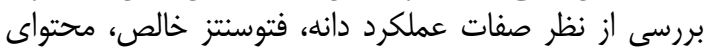

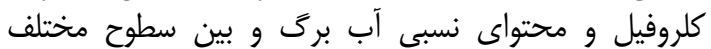

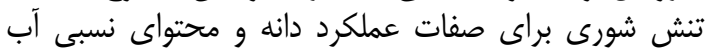

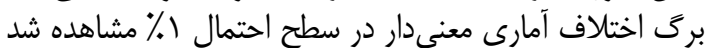

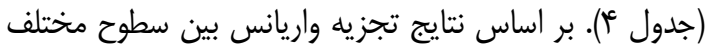
تنش و لاينهاى مختلف از نظر ميزان عناصر نسبت

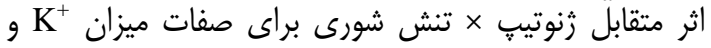
معنى $\mathrm{Na}^{+}$

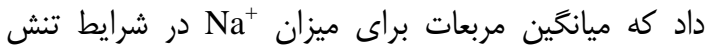

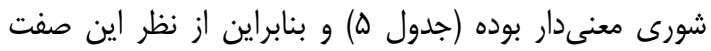

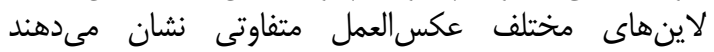

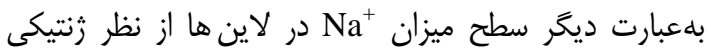

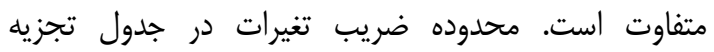

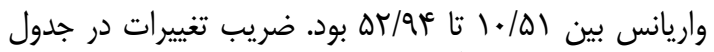

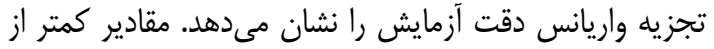

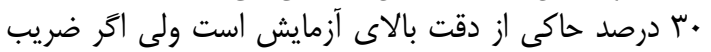

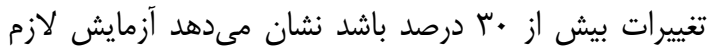

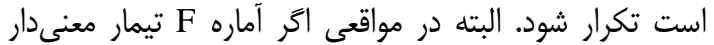

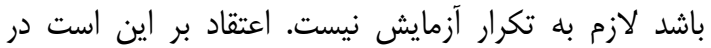

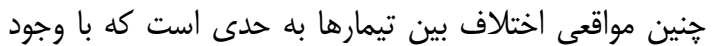

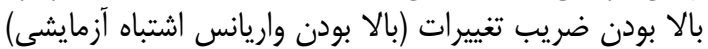

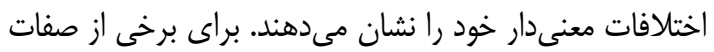

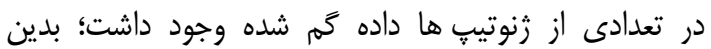

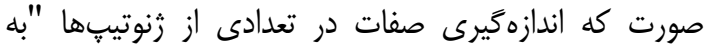

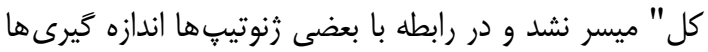

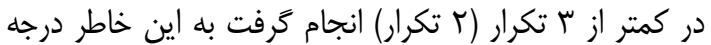

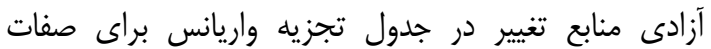
متفاوت است.
عملكرد دانه (q/^/ درصد) و كمترين ميزان كاهش مربوط به

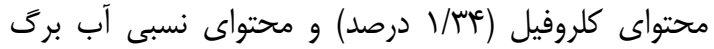

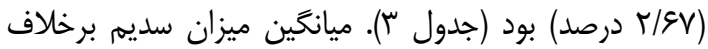

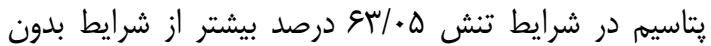
تنش بود (جدول سب).

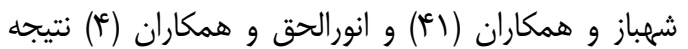

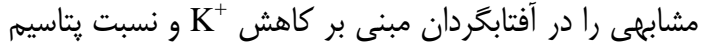

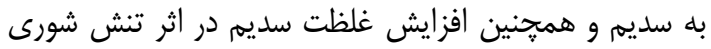

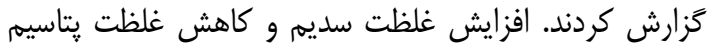

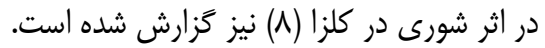

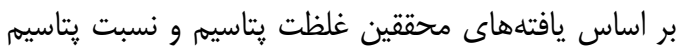

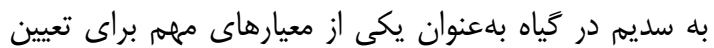

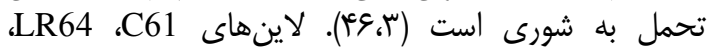

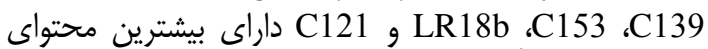
ا و نسبت $\mathrm{K}^{+}$

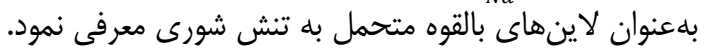

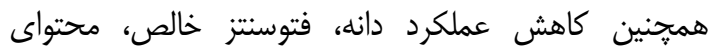

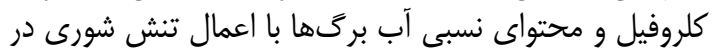

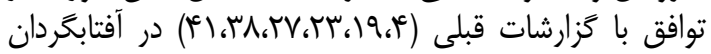
مىباشد.

كاهش محتواى نسبى آب برى در گياهان تحت تنش، از

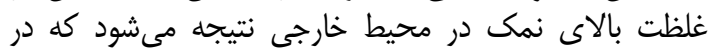

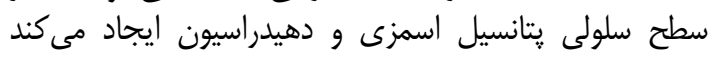

از طرفى تنش اكسيداتيو ناشى از افزايش محتواى گونهای إنهاى

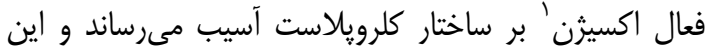

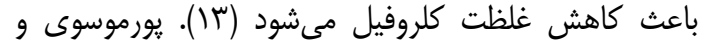

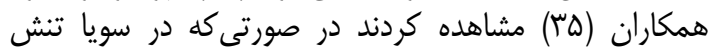

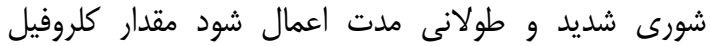

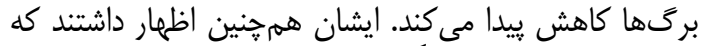

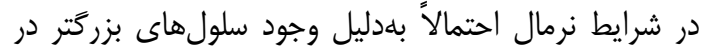

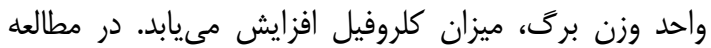

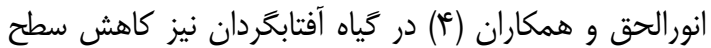

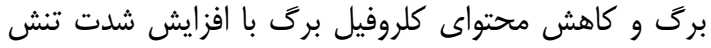
شورى مشاهده كَرديده است.

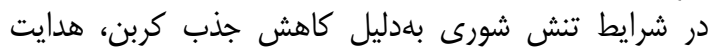

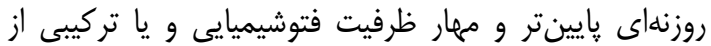
اين سه عامل، كاهش در ميزان فتوسنتز مشاهده شده است فتوني

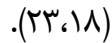
يافته هاى تحقيق حاضر نشان ميدهد كه كه براى صفت

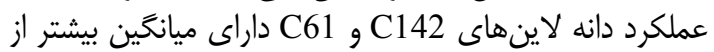


جدول س- مقادير آمارههاى توصيفى در لاينهاى آفتابخردان روغنى تحت شرايط نرمال و تنش شورى Table 3. Descriptive statistics in oily sunflower lines under normal and salinity stress conditions

\begin{tabular}{|c|c|c|c|c|c|c|c|c|c|}
\hline \multicolumn{2}{|c|}{ بهترين زنوتيت } & \multirow{2}{*}{ كاهش صفت شرايط تنش } & \multicolumn{2}{|c|}{ ضريب تنوع (\%) } & \multicolumn{2}{|c|}{ دامنه تغييرات } & \multicolumn{2}{|c|}{ ميانكين } & \multirow[t]{2}{*}{ صفات } \\
\hline شورى & 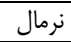 & & شورى & 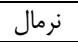 & 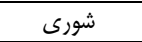 & 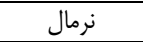 & شورى & نرمال & \\
\hline $\mathrm{C} 142$ & $\mathrm{C} 142$ & $9 / 4 \wedge$ & $\Delta N / T G$ & $\Delta / / 19$ & $. / \Delta Q-Y N / V^{F}$ & $\cdot / \mathcal{Q T}^{\mathrm{T}}-\mathrm{rV} / \Delta \mathrm{QV}$ & $11 / \mu r$ & $I T / \Delta T$ & عملكرد دانه (كرم) \\
\hline LR54 & $\mathrm{C} 70$ & $1 / \mu r$ & IT/Kr & 19 & $r Y / I-F V / g V$ & $\mid N / \Delta-\Delta \Gamma / Q T$ & $T \Delta / T V$ & $r \Delta / v^{\epsilon}$ & محتواى كلروفيل (عدد SPAD) \\
\hline $\mathrm{C} 115$ & LR39 & $r / T V$ & $r \mu / v$ & $r \mu / .9$ & $1 / 1 r-1 \% / 10$ & r/rI-IN/rq & $1 \cdot 1 \Delta \omega$ & $11 / \cdot 1$ & فتوسنتز خالص ( \\
\hline $\mathrm{C} 34$ & $\mathrm{C} 92$ & $r / 9 V$ & $9 / 9$ & $1 . / \Delta V$ & $\Delta r / \varepsilon-\Lambda \Gamma / \cdot 1$ & $\Delta \Delta / r q-q \uparrow / \leftarrow \Delta$ & $V \cdot 109$ & $V T / Q T$ & محتواى نسبى آب برى (\%) \\
\hline C139 & C 88 & $r \mu / \cdot \Lambda$ & rT/VA & $r F / \Delta T$ & $|/ V|-9 / 4$ & •/AV-V/Tr & 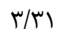 & $4 / r q$ & يتاسيم (َرم در ... أرم ماده خشك گياهى) \\
\hline $\mathrm{C} 113$ & $\mathrm{C} 120$ & $-g \mu / \cdot \omega$ & re/Aq & $r V / Q$ & $\cdot / \cdot \vee-\cdot / \uparrow \Lambda$ & $\cdot / \cdot t^{2}-\cdot / 4 r$ & $\cdot / \pi V$ &.$/ 19$ & سديم (كرم در ... آرم ماده خشى گياهى) \\
\hline C61 & $\mathrm{C} 75$ & $p v / \& q$ & gr/QH & FN/QS & $\Delta / \cdot r-q \mu / \uparrow \Lambda$ & $V / \& \Lambda-V T / \Lambda T$ & IV/rF & r & $\frac{\mathrm{K}^{+}}{\mathrm{Na}^{+}}$ \\
\hline
\end{tabular}

جدول أ- ميانخين مربعات تنش شورى، زنوتيي و اثر متقابل آنها بر روى عملكرد و برخى صفات فيزيولوزيك آفتابخردان روغنى Table 4. Mean squares of salinity stress, genotype and their interaction on yield and some physiological traits of oily sunflower

\begin{tabular}{|c|c|c|c|c|c|c|c|c|c|c|c|c|c|c|}
\hline \multicolumn{7}{|c|}{ ميانكين مربعات } & \multicolumn{7}{|c|}{ درجه آزادى } & \multirow[b]{2}{*}{$\frac{c}{c}$} \\
\hline 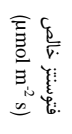 & 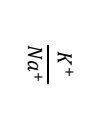 & 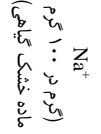 & 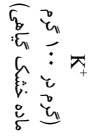 & S. & 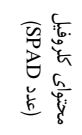 & 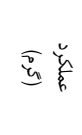 & $\frac{\varepsilon}{V} \xi_{G}$ & 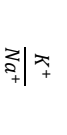 & $\underset{w_{+}}{Z}$ & 주 & $\stackrel{\pi}{2}$ & 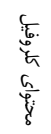 & 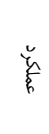 & \\
\hline$r Y / \& q^{n s}$ & 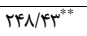 & $1 / / f^{* *}$ & $1 . . / .9^{* *}$ & $r V N / r^{* * *}$ & $\psi / \Delta \Lambda^{\mathrm{ns}}$ & Tq//9.** & 1 & 1 & 1 & 1 & 1 & 1 & 1 & شورى \\
\hline$V / \Delta r^{n s}$ & $r / \leftarrow \lambda^{\text {ns }}$ &.$/ .1^{*}$ & $1 / 91^{*}$ & $S T / \Psi^{\text {ns }}$ & $\kappa r / \kappa \Psi^{n s}$ & $r V / r T^{n s}$ & 94 & va & va & va & 99 & 1.5 & 90 & × رنورى \\
\hline $11 / 1 F$ & $r / r$ & $.1 . .9$ & $1 / \pi$ & $\Delta S / M$ & $\Gamma \Delta /{ }^{\prime} \Lambda$ & rQ/gr & ive & TVG & $r \Delta V$ & TVG & rTr & שפח & TM & خطا \\
\hline rI/QT & $r Y / W V$ & $\mid \mathrm{FV} / \cdot \Delta$ & $r q / r q$ & $1 . / 01$ & $19 / 98$ & $\Delta T / Q F$ & & & & & & & & $\begin{array}{c}\text { تغرييرات } \\
\text { تغر) }\end{array}$ \\
\hline
\end{tabular}

جدول ه- برشدهى اثر متقابل شورى و رنوتيب براى برخى صفات در آفتابخردان روغنى Table 5. Slicing the effect of interaction between salinity and genotypes for some traits in oily sunflower

\begin{tabular}{|c|c|c|c|c|}
\hline \multicolumn{2}{|c|}{ ميانگَين مربعات } & \multicolumn{2}{|c|}{ درجه آزادى } & \multirow[b]{2}{*}{ منابع تغييرات } \\
\hline 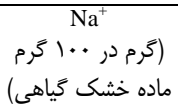 & 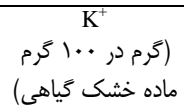 & $\mathrm{Na}^{+}$ & $\mathrm{K}^{+}$ & \\
\hline.$/ \cdot r^{* * *}$ & $1 / 41^{\mathrm{ns}}$ & vq & va & سطح شورى \& دسى زيمنس بر متر مربع \\
\hline$\cdot / \cdot 1^{\mathrm{ns}}$ & $r / 9 \Delta^{* *}$ & vq & va & نرمال \\
\hline
\end{tabular}

شورى سازگًار باشند (ع). اين اطلاعات براى تعيين والدين

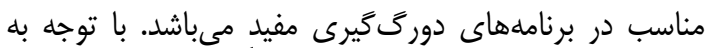

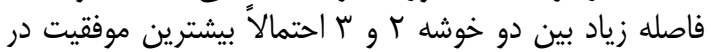

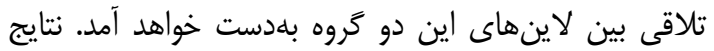

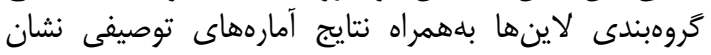

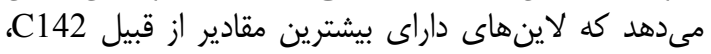

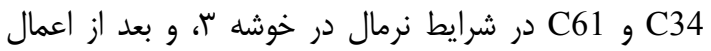

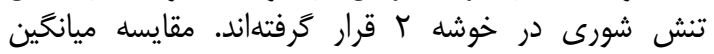
خوشههاى حاصل از تجزيه خوشهاى خلى با استفاده از آزمون

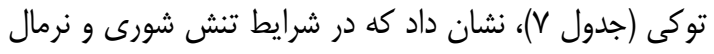

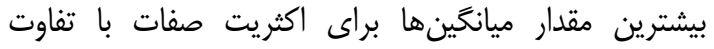

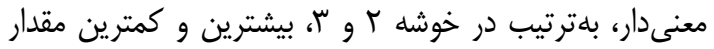

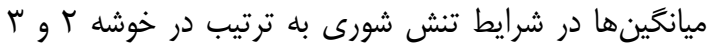
قابل مشاهده است.

\section{كرووبندى لاينهاى مورد مطالعه آفتابكردان}

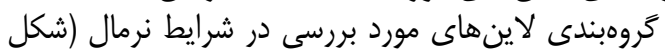

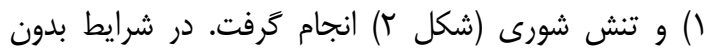

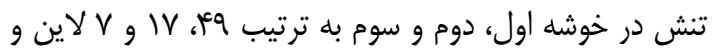

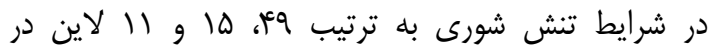

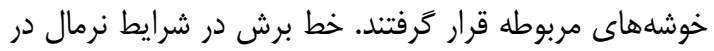

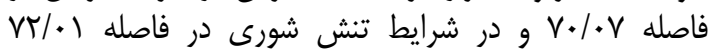

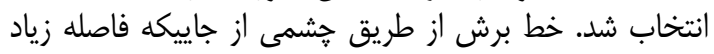

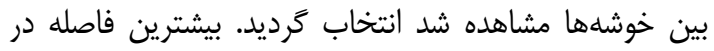

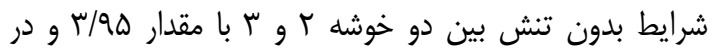

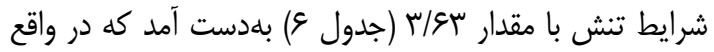

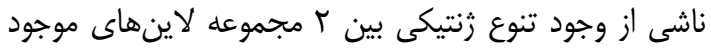

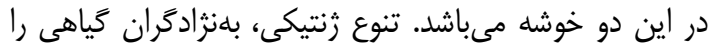

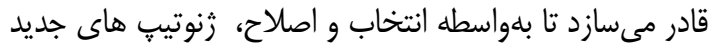
و با عملكرد بيشتر توليد كنند كه به تغييرات بهات محيطى مانند 
191

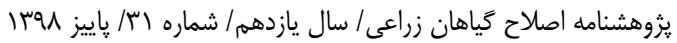

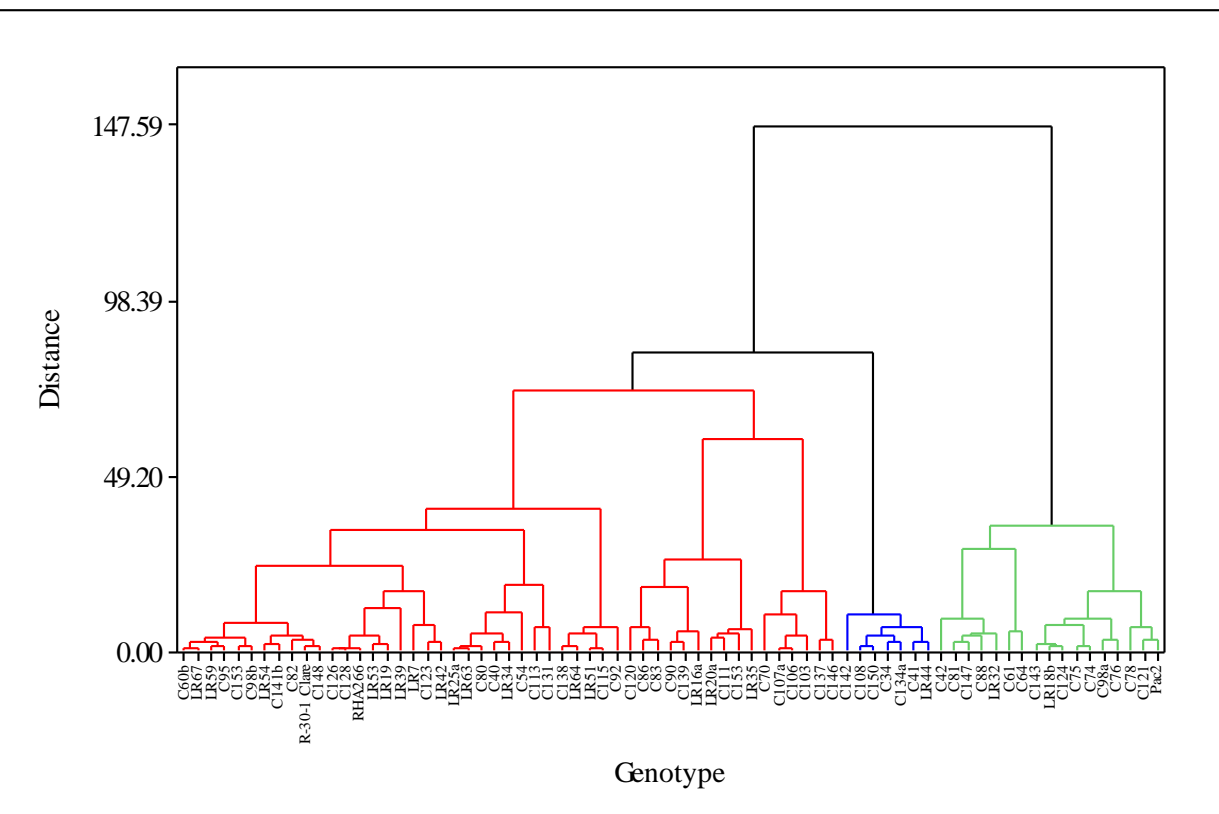

شكل ا - دندروگرام حاصل از تجزيه خوشهاى لاينهاى خويش آميخته نوتر كيب آفتابخردان روغنى در شرايط بدون تنش شورى به روش Ward

Figure 1. Dendrogram resulting from cluster analysis of oily sunflower recombinant inbred lines in non-salt stressed conditions by using Ward method

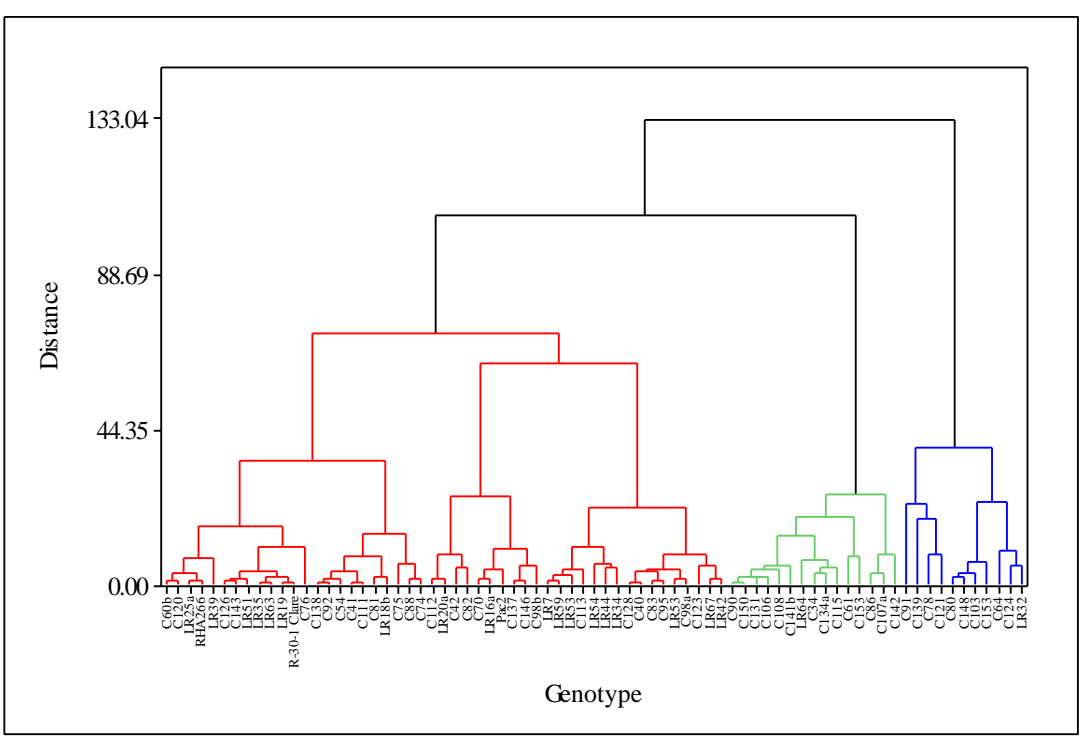

شكل r- دندروكرام حاصل از تجزيه خوشهاى لاينهاى خويشآميخته نوتر كيب آفنابخردان روغنى در شرايط تنش شورى به روش Ward

Figure 2. Dendrogram resulting from cluster analysis of oily sunflower recombinant inbred lines in salt stressed conditions by using Ward method 
Table 6. Calculated intervals between groups resulting from cluster analysis

$$
\text { جدول צ- فواصل محاسبه شده بين گروههاى حاصل از تجزيه خوشهاى }
$$

\begin{tabular}{|c|c|c|c|c|}
\hline كلاستر r & كلاستر r & كلاستر 1 & تعداد لاين در كلاستر & كلاستر \\
\hline \multicolumn{5}{|c|}{ شرايط بدون تنش شورى (Non-salt stress conditions) } \\
\hline & & • & 19 & كلاستر 1 \\
\hline$\cdot$ & r/१८ & $r|q|$ & v & كلاستر r \\
\hline \multicolumn{5}{|c|}{ شرايط تنش شورى (Salt stress conditions) } \\
\hline & & $\cdot$ & 19 & كلاستر I \\
\hline$\cdot$ & 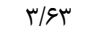 & $r / \Delta$ & 11 & كلاستر r \\
\hline
\end{tabular}

جدول V- مقايسهى ميانخين گروههاى حاصل از تجزيه خوشهاى به روش Ward با استفاده از آزمون توكى Table 7. Mean comparison among groups resulting from Ward cluster analysis by using Tukey test

\begin{tabular}{|c|c|c|c|}
\hline \multicolumn{3}{|c|}{ 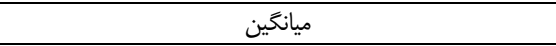 } & \multirow{2}{*}{ 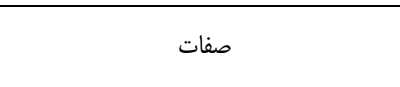 } \\
\hline كلاستر r & كلاستر r & كلاستر 1 & \\
\hline \multicolumn{4}{|c|}{ شرايط بدون تنش شورى (Non-salt stress conditions) } \\
\hline$r \mu / \mu F^{b}$ & $9 / 1 \Lambda^{a}$ & $11 / \wedge \Delta^{\mathrm{a}}$ & عملكرد دانه (كرم) \\
\hline$f \cdot / v^{c b}$ & $M \backslash / q^{a}$ & $r \varepsilon / q V^{b}$ & محتواى كلروفيل (عدد SPAD) \\
\hline$I T / V^{b}$ & $\Lambda / \wedge \Delta^{a}$ & $11 / \xi^{\mathrm{b}}$ & فتوسنتز خالص(ب mol m²s) \\
\hline$V N / \Delta F^{b}$ & $q \mathrm{~V} / \cdot \mathrm{r}^{\mathrm{a}}$ & $V r / A v^{a b}$ & محتواى نسبى آب برى (٪) \\
\hline$r / 1 \varphi^{\mathrm{a}}$ & $\Delta / \varphi^{\epsilon} c^{b}$ & $r / a r^{a}$ & يتاسيم (كرم در ... أرم ماده خشك كياهى) \\
\hline . / $1 \mathrm{rra}^{\mathrm{a}}$ &.$/ 1 r \Delta^{\mathrm{a}}$ & $\cdot / \mathrm{M}^{\mathrm{b}}$ & سديم (كرم در ... اَرم ماده خشك گياهى) \\
\hline \multicolumn{4}{|c|}{ شرايط تنش شورى (Salt stress conditions) } \\
\hline $9 / 99^{a}$ & $r \cdot / 9)^{b}$ & $\Lambda / V)^{a}$ & عملكرد دانه (كرم) \\
\hline$r r / \cdot \Lambda^{\mathrm{a}}$ & re/r & $r \Delta / v \Delta^{b}$ & محتواى كلروفيل (عدد SPAD) \\
\hline$V / \Delta \Delta^{a}$ & $11 / \leftarrow \Delta^{\mathrm{b}}$ & $1 . / 9 r^{\mathrm{b}}$ & فتوسنتز خالص(بmol m² \\
\hline$\varepsilon \Delta / / \varepsilon^{\mathrm{a}}$ & $V T / T F^{b}$ & $\checkmark T / \omega^{b}$ & محتواى نسبى آب برى (٪) \\
\hline$r / 1 Q^{\mathrm{b}}$ & $r / \cdot r^{\mathrm{a}}$ & $r / / V^{a}$ & يتاسيم (كرم در ... آرم ماده خشك كياهى) \\
\hline$\cdot / 4 q^{\mathrm{a}}$ & $\cdot / \pi r^{\mathrm{a}}$ & $\cdot / r V^{a}$ & سديم (كرم در ... كرم ماده خشك گياهى) \\
\hline
\end{tabular}

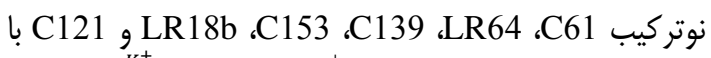
دارا بودن بيشترين محتواى

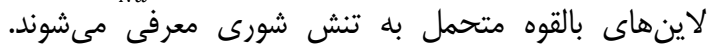

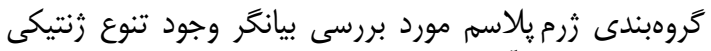

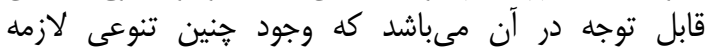

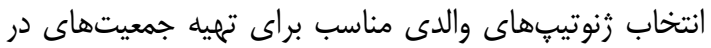

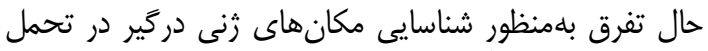

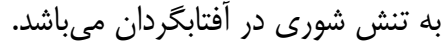

تنش شورى باعث كاهش مقادير كليه صفات بهجز سديم

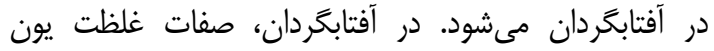

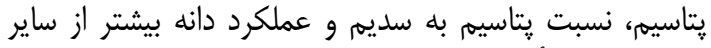

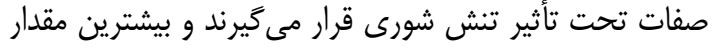

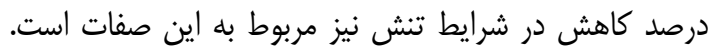

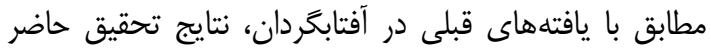

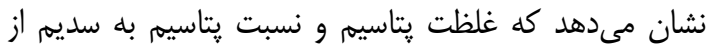

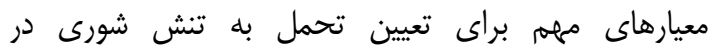
آفتابخردان است. بر اين اساس، لاينهاى خويش تعل آميخته 
1. Achakzai, A.K., K.M. Rahman, M. Yaqoob, A. Sarangzai, M.Y.K. Barozai and M. Din. 2015. Stem and leaf response of sunflower hybrids to salt stress. Pakistan Journal of Botany, 47: 2063-2067.

2. Ahmadpour, S., O. Sofalian and R. Darvishzadeh. 2017. Genetic diversity of oily sunflower lines under normal and salt stress conditions using multivariate statistical analysis methods. Iranian Journal of Field Crop Science, 48(2): 399-411.

3. Akram, M., M.Y. Ashraf, R. Ahmad, E.A. Waraich, J. Iqbal and M. Mohsan. 2010. Screening for salt tolerance in maize (Zea mays L.) hybrids at an early seedling stage. Pakistan Journal of Botany, 42: 141-154.

4. Anwar-ul-Haq, M., S. Akram, J. Akhtar, M. Saqib, Z.A. Saqib, G.H. Abbasi and M. Jan. 2013. Morphol- ohysiological characthrization of sunflower genotypes (Helianthus annuus L.) under saline condition. Pakistan Journal of Agricultural Sciences, 50: 49-54.

5. Arzani, A. 2008. Improving salinity tolerance in crop plants: biotechnology view. In Vitro Cellular \& Developmental Biology-Plant, 44: 373-383.

6. Ashraf, M. and M.R. Foolad. 2013. Crop breeding for salt tolerance in the era of molecular markers and marker-assisted selection. Plant Breeding, 132: 10-20.

7. Asia Khaton, M., S. Qureshi and M.K. Hssain. 2000. Effect of salinity on some yield parameters of sunflower. International Journal of Agriculture and Biology, 4: 382-384.

8. Bybordi, A., S.J. Tabatabaei and A. Ahmadey. 2010. $\mathrm{NaCl}$ salinity effect on qualitative, quantitative and physiological attributes of winter canola (Brassica napus L.) cultivars. Journal of Water and Soil, 24: 334-346.

9. Canama, T., X. Li, J. Holowachukb, M. Yu, J. Xia, R. Mandal, R. Krishnamurthy, S. Bouatra, I. Sinelnikov, B. Yu, L. Grenkow, D.S. Wishart, H. Steppuhn, K.C. Falk, T.J. Dumonceaux and M.Y. Gruber. 2013. Differential metabolite profiles and salinity tolerance between two genetically related brown-seeded and yellow-seeded Brassica carinata lines. Plant Science, 198: 17-26.

10. Dashti, H., M.R. Naghavi and A. Tajabadipour. 2010. Genetic analysis of salinity tolerance in a bread wheat cross. Journal of Agricultural Science and Technology, 12: 347-356.

11. Dehghani, M., G.H. Shiresmaeili and F. Qolamhosein. 2010. Effect of irrigation water salinity on three commercial sunflower hybrids. Water Research in Agriculture, 28(1): 191-199.

12. Demir, M. and A. Ozturk. 2003. Effect of different soil salinity levels on germination and seedling growth of safflower (Carthamus tinctorius L.). Turkish Journal of Agriculture and Forestry, 27: 224227.

13. Desingh, R. and G. Kanagaraj. 2007. Influence of salinity stress on photosynthesis and antioxidative systems in two cotton varieties. General and Applied Plant Physiology, 33: 221-234.

14. Ebrahimi, R. and S.C. Bhatla. 2012. Ion distribution measured by electron probe X-ray microanalysis in apoplastic \& symplastic pathways in root cells in sunflower plants grown in saline medium. Journal Biosciences, 37: 713-721.

15. FAO (Food and Agriculture Organization) Rome. 2016. http://faostat.fao.org/.

16. Faraghei, S.H., M. Farshadfar and E. Farshadfar. 2007 Study of chemical composition and nutrition value of perennial Lucerne (Medicago sativa L.) and genetic diversity based on SDS- PAGE marker. Iranian Journal of Rangelands and Forests Plant Breeding and Genetic Research, 15: 196-210.

17. Francois, L.E. 1996. Salinity effects on four sunflower hybrids. Agronomy Journal, 88(2): 215-219.

18. Gaballah, M.S., S.A. Ouda, M.S. Mendour and M.M. Rady. 2006. Predicting the role of antioxidant and irrigation on sunflower yield grown under saline conditions. Proceeding of International Conference: ESTW, 30-35.

19. Gunes, A., A. Inal, E. Guneri Bagci and D.J. Pilbeam. 2007. Silicon-mediated changes of some physiological andenzymatic parameters symptomatic for oxidative stress in spinach and tomato grown in sodic-B toxic soil. Plant and Soil, 290: 103-114.

20. Hameed, M., T. Nawaz, M. Ashraf, N. Naz, R. Batool, M.S.A. Ahmad and A. Riaz. 2013. Physioanatomical adaptations in response to salt stress in Sporobolus arabicus (Poaceae) from the Salt Range, Pakistan. Turkish Journal of Botany, 37: 715-724.

21. Hasegawa, P.M. 2013. Sodium $\left(\mathrm{Na}^{+}\right)$homeostasis and salt tolerance of plants. Environmental and Experimental Botany, 150: 19-31.

22. Heidari, A., M. Toorchi, A. Bandehag, and M.R. Shakiba. 2011. Effect of NaCl Stress on Growth, Water Relations, Organic and Inorganic Osmolytes Accumulation in Sunflower (Helianthus annuus L.) Lines. Universal Journal of Environmental Research and Technology, 3: 351-362.

23. Hussain, S.A., J. Akhtar, M.A. Haq, M.A. Riaz and Saqib, Z.A. 2008. Ionic concentration and growth response of Sunflower (Helianthus annuus L.) genotypes under saline and/ or sodic water application. Soil \& Environment, 27: 177-184.

24. Johnson, R.C., R.E. Witters, and D.M. Sanches. 1992. Daily pattern of apparent photosynthesis and evapotranspiration in developing winter wheat. Agronomy Journal, 73: 414-418.

25. Kafi, M., A. Berzai, M. Salehi, A. Kamandi, A. Masumi and C. Nabati. 2009. Physiology of Environmental Stresses in Plants. Ferdowsi University of Mashhad, Iran, 502 pp. 
26. Katsuhara, M., Y.T. Hanba, K. Shiratake and M. Maeshima. 2008. Expanding roles of plant aquaporins in plasma membranes and cell organelles. Functional Plant Biology, 35: 1-14.

27. Khan, A., I. Iqbal, I. Ahmad, N. Nawaz and M. Navaz. 2014. Role of prolin to induce salinity tolerance in sunflower (Helianthus annuus L.). Science, Technology and Development, 33: 88-93.

28. Khan, M.A. and S. Gulzar. 2003. Germination responses of Sporobolus ioclados: A saline desert grass. Journal of Arid Environments, 55: 453-A464.

29. Kumar, K., M. Kumar, S.R. Kim, H. Ryu and Y.G. Cho. 2013. Insinghts into genomics of salt stress responses in rice. Rice, 6: 27.

30. Liu, J. and D.C. Shi. 2010. Photosynthesis, chlorophyll fluorescence, inorganic ion and organic acid accumulations of sunflower in responses to salt and salt-alkaline mixed stress. Photosynthetica, 48: 127-134.

31. Marschner, H. 1995. Mineral nutrition of higher plants. 2nd Academic Press. Ltd. London.

32. Maas, E.V. and G.J. Hoffman. 1977. Crop salt tolerance current assessment. ASCE J. Irrig. Drainage Div., 103(IR2): 115-134.

33. Morsali Aghajari, F. 2015. Identification of QTL controlling traits in sunflower under different levels of salt stress. M.Sc. Thesis, Urmia University, Urmia, Iran, 192 pp.

34. Okhovatian Ardakani, A.R., M. Mehrabanian, F. Dehghani and A. Ak-barzadeh. 2010. Salt tolerance evaluation and relative comparison in cuttings of different pomegranate cultivars. Plant, Soil and Environment, 56: 176-185.

35. Poor Mousavi, M., M. Galavy and J. Daneshian. 2007. Effects of drought and manure on water content and membrane stability and leaf chlorophyll content of soybean. Journal of Agriculture Science and Natural Resources, 14: 125-133.

36. Rady, M.M., M.S. Sadak, H.M.S. El-Bassiouny and A.A. Abd El-Monem. 2011. Alleviation of the adverse effects of salinity stress in sunflower cultivars using nicotinamide and $\alpha$-Tocopherol. Australian Journal of Basic and Applied Sciences, 5: 342-355.

37. Rai, M.K., R.K. Kalia, R. Singh, M.P. Gangola and A.K. Dhawan. 2011. Developing stress tolerant plants through in vitro selection-An overview of the recent progress. Environmental \& Experimental Botany, 71: 89-98.

38. Reddy, M.P. and A.B. Vora. 2005. Salinity induced changes in pigment composition and chlorophyllase activity of chelidonium. Indian Journal of Plant Physiology, 29: 331-334.

39. Ryan, J., G. Estefan and A. Rashid. 2001. Soil and Plant Analysis Laboratory Manual. Jointly published by the International Centre Agricultural Research in Dry Areas (ICARDA), Aleppo, Syria and National Agric. Res. Centre (NARC), Islamabad.

40. Seiler, G., C.C. Jan. 2010. Basic information. In Hu, J., Seiler, G. and Kole, C. (eds). Genetics, genomics and breeding of sunflower, 1-50 pp.

41. Shahbaz, M., M. Ashraf, N. Akram, A. Hanif, S. Hameed, S. Joham, and R. Rehman, 2011. Saltinduced modulation in growth, photosynthetic capacity, proline content and ion accumulation in sunflower (Helianthus annuus L.). Acta physiologiae Plantarum, 33: 1113-1122.

42. Shahin Kaleybar, B., Gh. Nematzadeh, S.H.R. Hashemi, H. Askari and S. Kabirnataj. 2013. Physiological and genetic responses of halophyte Aeluropus littoralis to salinity. Journal of Crop Breeding, 5(12): 15-29.

43. Sharbatkhari, M., S. Galeshi, Z.S. Shobbar, B. Nakhoda and M. Shahbazi. 2013. Assessment of agrophysiological traits for salt tolerance in drought-tolerant wheat genotypes. International Journal of Plant Production, 7(3): 437-453.

44. Shokrpour, M. and E. Esfandiari. 2014. Grouping different wheat varieties for salt tolerance using some biochemical and physiological indices. Journal of Crop Breeding, 6(14): 54-66.

45. Silveira, J.A., R.A. Viegas, I.M. Rocha, A.C. Moreira, R.A. Moreira and J.T. Oliveira. 2003. Proline accumulation and glutamine synthetase activity are increased by salt- induced proteolysis in cashew leaves. Plant Physiology, 160: 115-123.

46. Summart, J., P. Thanonkeo, S. Panichajakul, P. Prathepha and M.T. McManus. 2010. Effect of salt stress on growth, inorganic ion and proline accumulation in Thai aromatic rice, Khao Dawk Mali 105, callus culture. African Journal of Biotechnology, 9: 145- 152.

47. Tezara, W., V. Mitchell, S.P. Driscoll and W. Lawlor. 2002. Effects of water deficit and its interaction with $\mathrm{CO} 2$ supply on biochemistry and physiology of photosynthesis in sunflower. Journal of Experimental Botany, 53: 1781-1791.

48. USDA-ARS. 2008. Research Databases. Bibliography on Salt Tolerance. George E. Brown, Jr. Salinity Lab. US Dep. Agric., Agric. Res. Serv. Riverside, CA. http://www. ars.usda.gov/Services/docs.htm?docid=8908.

49. Xu Y. 2002. Global view of QTL: rice as a model. In: Kang MS, editor. Quantitative genetics, genomics and plant breeding. Wallingford (UK): CAB Int., 109-134.

50. Younesi-Melerdi, E., Gh. Nematzadeh and E. Shokri. 2018. Isolation and gene expression investigation in photosynthetic isoform of phosphoenolpyruvate carboxylase gene in halophytic grass Aeluropus littoralis under salinity stress. Journal of Crop Breeding, 9(24): 69-78. 


\title{
Selection of Salinity Tolerant Lines of Sunflower using some Physiological Characteristics
}

\author{
Fariba Morsali Aghajari ${ }^{1}$, Reza Darvishzadeh $^{2}$, Hamid Hatami Maleki $^{3}$, Esmail \\ Gholinezhad $^{4}$ and Abdolghader Kalantar ${ }^{5}$ \\ 1- M.Sc. in Plant Breeding, Department of Plant Breeding and Biotechnology, Faculty of Agriculture, Urmia \\ University, Urmia, Iran \\ 2- Professor, Department of Plant Breeding and Biotechnology, Faculty of Agriculture, Urmia University, Urmia, \\ Iran, (Corresponding Author: r.darvishzadeh@urmia.ac.ir) \\ 3- Assistant Professor, Department of Plant Genetics and Production, Faculty of Agriculture, University of \\ Maragheh, Maragheh, Iran \\ 4- Associate Professor Department of Agricultural Sciences, Payame Noor University, Tehran, Iran \\ 5-PhD in Agronomy, Department of Agronomy, Faculty of Agriculture, Urmia University, Urmia, Iran \\ Recueved: January 1,2018 \\ Accepted: September 30, 2018
}

\begin{abstract}
Abiotic stress such as drought and salinity stresses considered as important problem in arid and semi-arid regions which have negative impacts on the growth and development of plants. In addition to toxicity effect of salinity stress, it causes drought stress. In this research, for selection of salinity tolerant lines of sunflower using physiological indices, a sunflower germplasm including 100 inbred lines were inspected under both normal and salinity $\left(6 \mathrm{ds} / \mathrm{m}^{2}\right)$ state. Experiment was done in pots which arrayed considering factorial experiment based on complete randomized design with three replications in outdoor conditions. The results showed the significant effect of salinity on seed yield, relative water content, $\mathrm{Na}^{+}, \mathrm{K}^{+}$and $\mathrm{K}^{+} / \mathrm{Na}^{+}$ratio. The effect of genotype was significant on net photosynthesis and chlorophyll content in addition to above mentioned traits. Mean value of studied characters except of sodium concentration were reduced under salt stress compared to normal. In this research, most reduction was observed in $\mathrm{K}^{+} / \mathrm{Na}^{+}$ratio $(47.49 \%), \mathrm{K}^{+}(23.08 \%)$ and grain yield $(13.84 \%)$ and the lowest reduction was observed in chlorophyll content $(1.34 \%)$ and leaf relative water content $(2.67 \%)$. Regarding response of the studied lines against salinity stress, inspected germplasm was separated into three groups. Cluster mean comparisons using Tukey test in salinity stress conditions revealed that the highest and lowest mean of traits were observed in clusters II and III, respectively. Recombinant inbred lines including C61, C34, C134a and C153 showed the highest values for most of studied traits specially for $\mathrm{K}^{+}$content and $\mathrm{K}^{+} / \mathrm{Na}^{+}$ratio. Potassium and potassium/sodium ratio in plant are one of the important criteria for determining salt tolerance; therefore, these lines are potentially introduced as salt tolerant lines.
\end{abstract}

Keywords: $\mathrm{K}^{+} / \mathrm{Na}^{+}$ratio, Net photosynthesis, Oily sunflower, Relative water content, Salinity stress 